\title{
Estado peruano, liberalismo y tierras indígenas en la precordillera de Arica (1854-1880)*
}

\author{
Peruvian State, liberalism and indigenous lands \\ in the foothills of Arica (1854-1880) \\ Rodrigo Ruz ${ }^{* *}$ \\ Héctor González ${ }^{* * *}$ \\ Universidad de Tarapacá, Arica, Chile
}

Recibido: 22 de octubre de 2012. Aprobado: 01 de abril de 2013.

\begin{abstract}
Resumen
El proyecto político liberal impulsado por el Estado peruano a partir de su independencia, pasó por vaivenes que retrasaron su implementación hacia la segunda mitad del siglo XIX, momento en el cual las políticas liberales se desplegaron en diversas aristas. De ellas se estudian las medidas conducentes al establecimiento de la propiedad privada en el ex sur peruano (actual norte grande chileno). Estas afectaron antiguos pactos, protocolos, concepciones territoriales y prácticas jurídicas acuñadas en momentos previos por parte de la población indígena regional. Esta investigación analiza dicho marco, tomando como estudio de caso el proceso de presión, reacción y litigio por tierras indígenas en la precordillera de Arica.
\end{abstract}

Palabras claves: Estado peruano, liberalismo, propiedad de la tierra

Este artículo es resultado del proyecto FONDECYT N ${ }^{\circ}$ 1070032. Convenio de Desempeño Universidad de Tarapacá, Ministerio de Educación.

* Universidad de Tarapacá, Departamento de Ciencias Históricas y Geográficas, Arica, Chile. Correo electrónico: rruz@uta.cl

*** Universidad de Tarapacá, Departamento de Antropología, Arica, Chile. Correo electrónico: hgonzale@uta.cl 


\begin{abstract}
The liberal political project driven by the Peruvian government after independence went through ups and downs that delayed its implementation towards the second half of the nineteenth century, moment in which liberal policies were deployed at various levels. Of these, this paper studies the measures leading to the establishment of private property in the former southern Peru (now Chile's Norte Grande). These measures affected ancient covenants, protocols, territorial conceptions and legal practices minted in previous times by the regional indigenous population. This research analyzes said context, taking as a case study the process of pressure, reaction and indigenous land disputes in the foothills of Arica.
\end{abstract}

Keywords: Peruvian state, liberalism, ownership of the land

\title{
Introducción
}

Las comunidades de la precordillera ariqueña (extremo norte de Chile) son entidades históricas que se han construido sobre la base del reconocimiento de los terrenos donde desarrollan sus actividades sociales, productivas y rituales, y a la presencia de sistemas que regulan el uso y acceso a las tierras definidas como "comunitarias" o de "utilización colectiva".

El análisis de sistemas de regulación territorial y acceso a la propiedad propuestos por el Estado colonial español y los Estados nacionales peruano y chileno, han demostrado que las comunidades y población indígenas se relacionaron con estructuras y legislaciones estatales para legitimar sus derechos sobre la tierra (González y Gundermann, 2009). Esta vinculación posee manifestaciones tempranas, a partir de la propuesta colonial de establecimiento de pactos tributarios entre la Corona española y la "República de Indios". Este pacto, aunque con modificaciones, se extiende hasta mediados del siglo XIX, a través del sistema especial de contribución de indígenas que ordenaba las relaciones productivas durante la naciente República peruana, bajo un sistema que organizó repartos de tierras en pro de asegurar su productividad a cambio de un cumplimiento tributario de carácter pecuniario.

En 1854, el presidente del Perú Ramón Castilla abolió definitivamente la contribución indígena. Con ello eliminaba uno de los más persistentes resabios coloniales en- 
frentados por el proyecto peruano. El período comprendido entre 1854-1880, representa la aplicación de las medidas liberales esbozadas, pero no concretadas al momento de la independencia. El Estado concentró sus políticas de desarrollo al ámbito individual, considerando plenamente a la población indígena en su calidad de ciudadanos, extendiendo sus derechos al de la propiedad sobre la tierra, promoviendo el uso y tenencia individual de la misma.

¿Cómo se manifestó en términos concretos la retirada del sistema neocolonial de tributación? ¿Qué consecuencias tuvo para los indígenas la desaparición de los sistemas de resguardo comunitario y la emergencia del sistema de apropiación individual de la tierra? ¿Cuáles son las reacciones y expresiones de este escenario en el espacio andino del extremo norte chileno?

Esta investigación se concentra en la reacción de la población del norte chileno, frente a la desaparición del sistema neocolonial que aseguraba el acceso a la tierra, dando paso al renovado sistema liberal que habría promovido un nuevo trato hacia la población indígena, trayendo consigo nuevas estrategias para definir el acceso a la tierra, enfrentar la legislación y disposiciones estatales.

\section{Las tierras indígenas durante el período peruano republicano temprano (1821-1854)}

Historiadores y legistas coinciden acerca de la importancia del rol ejercido por el pago de "tributo" durante el período colonial, que otorgaba derechos de usufructo sobre la tierra a las comunidades indígenas, en consonancia con la legislación indiana sobre la intangibilidad de estas tierras y la prohibición de su traspaso a terceros no indígenas (Ots Capdequi, 1968; Dougnac, 1994). Este sistema de tributación formó parte del denominado Pacto Colonial entre la Corona y los indígenas.

Con la independencia del Perú, se intentaron aplicar políticas de espíritu liberal que buscaban eliminar el tributo y las comunidades de indios, entendidos como resabios del oprobioso sistema colonial. De esta manera, los indígenas podían transformarse en propietarios individuales de sus antiguas tierras de comunidad. Estas medidas apuntaban a la creación de una amplia clase de pequeños propietarios agrícolas, con derechos de propiedad no limitados, de libre disposición, es decir, posibles de ser libremente enaje- 
nados y heredados, ya que la propiedad era posesión de los individuos y no de grupos corporativos (como la Iglesia, municipios o comunidades) ${ }^{1}$.

Sin embargo, presionado por la falta de recursos fiscales, en 1826, el gobierno bolivariano reintrodujo el tributo indio, bajo la denominación de "contribución de indígenas". Junto con mejorar la economía nacional y regional, esta contribución también delimitó las relaciones entre el Estado y los "indios" de una manera parecida a la existente durante el período colonial (Sánchez-Albornoz, 1978). La diferencia era que ahora los "indígenas" ya no eran la población colonizada que "tributaba" a sus vencedores, sino ciudadanos que "contribuían" al sostenimiento de su Estado. De todas maneras, el nuevo sistema tributario presentó también algunos cambios respecto del régimen colonial. Los principales tenían que ver con la "individualización" del pago, la desaparición de las categorías de "originarios" y "forasteros" y el congelamiento de los montos de pago ${ }^{2}$.

\section{La aplicación definitiva del modelo liberal y su impacto en las tierras comunales (1854-1880)}

El año 1854, el presidente Ramón Castilla eliminó definitivamente la contribución especial de indígenas, aprovechando la mejoría económica producida por la bonanza fiscal dejada por la extracción de guano, además de la activación del mercado externo en las haciendas y la consolidación de un mercado empresarial y comercial (González y Gundermann, 2009)3. Un par de años antes, en 1852, el nuevo Código Civil peruano ya había obviado la existencia de las comunidades indígenas (Figallo, 2007) ${ }^{4}$.

Esta decisión marca simbólicamente el fin del trato gubernamental de los indios como miembros de un grupo corporativo. La abolición definitiva de la tributación especial de "indígenas", permitió la instalación del postergado ideal liberal independentista. De hecho, el decreto apuntaba expresamente a "poner en práctica los derechos de libertad, igualdad y propiedad" garantizados en la Constitución. De esta manera, en adelante

1 Para una visión del liberalismo en Perú en relación a las comunidades indígenas durante el siglo XIX, véase Jacobsen (1997). Para el caso de Bolivia se puede consultar Platt (1982) y Langer (1988). Para la situación del área que corresponde actualmente al norte de Chile, véase González (2002); González y Gundermann (2009).

2 Para una mayor especificación de las continuidades y discontinuidades entre el sistema tributario indígena colonial y republicano se pueden consultar los trabajos de Contreras (1980); y González (2002).

3 Según Jacobsen (1997), la bonanza fiscal no solo permitió rebajar o abolir ciertas tasas, sino que también contribuyó a generar un marco más amplio de discusión acerca de la relación entre Estado y sociedad.

4 Esta situación se mantuvo hasta las primeras décadas del siglo XX, momento en el cual la legislación peruana retomó y se hizo cargo de las comunidades indígenas, sus necesidades y exigencias (Figallo, 2007). 
el Estado podía concentrar sus políticas de desarrollo en el ámbito individual, considerando a la población indígena en su calidad de ciudadanos y no como sujetos especiales dentro de una nación de iguales (González, 2002).

La aplicación de estos principios al ámbito territorial, significó la creación de la categoría tributaria de "contribución predial", un gravamen aplicable a la propiedad agrícola de acuerdo a sus ingresos. Esta iniciativa extendió los derechos ciudadanos a la propiedad sobre la tierra, estimándose que la mayoría de los pequeños agricultores indígenas debían quedar exentos de pagar estas tasas, ya que sus terrenos producían rentas inferiores al mínimo calculado (González, 2002).

Aunque durante este período no se sancionó legalmente si las tierras indígenas debían ser consideradas concesión en usufructo o propiedad plena ${ }^{5}$, se ha planteado que se extendió el lenguaje y la práctica de la propiedad privada en la población indígena y que este proceso habría ocasionado un aumento de conflictos y litigios sobre la tierra, que quedó plasmado en las agencias estatales y notarías públicas. De todas maneras, el avance de la propiedad privada en la zona de estudio, solo se consolidará con la incorporación del territorio a la administración chilena (Ruz y Díaz, 2011).

\section{La presión sobre las antiguas tierras comunales: el caso de Putre}

La situación política y legislativa que se abre a partir de mediados del siglo XIX, implica el término de la protección que entregaba a las tierras de indígenas el sistema de tributación neocolonial del período republicano peruano temprano. El énfasis definitivo de apropiación individual del nuevo sistema de contribución predial, trae consigo también la erosión de los antiguos sistemas de regulación comunitaria del acceso a la tierra. Las consecuencias de esta nueva situación son poco conocidas para los aymara de la precordillera y el altiplano del Norte Grande chileno.

Este trabajo se centra en la localidad de Putre, sobre la que contamos con registros documentales para el período de análisis, los que se encuentran en diversos depósitos regionales, nacionales e internacionales. Se trata, fundamentalmente, de solicitudes de tierras que dieron lugar a litigios, que permiten observar los procedimientos utilizados

Solo en 1876, durante la presidencia de Manuel Pardo, se emitió un decreto que confirmaba el pleno derecho de propiedad para las comunidades campesinas de origen indígena (González y Gundermann, 2009). 
por estos indígenas, además de las consecuencias de su inserción en el nuevo orden jurídico imperante durante la segunda mitad del siglo XIX ${ }^{6}$.

Putre, como el resto de las comunidades de sierra, se articula en torno a un poblado central rodeado por un territorio que incluye sectores de cultivo bajo sistemas de regadío y terrenos de aptitud ganadera, de secano (pastales) y eventualmente regados o inundados naturalmente por pequeños cursos de agua (bofedales). Los casos que se analizan en este trabajo corresponden a solicitudes efectuadas sobre estos diferentes tipos de tierras.

El análisis de lo ocurrido con Putre durante este período, puede servir también para entender de mejor manera lo ocurrido posteriormente en esta localidad, ya que fue una de las pocas corporaciones territoriales que constituyó propiedad sobre tierras de uso colectivo durante el período "chileno", definiendo un amplio perímetro territorial como propiedad particular entre 1909-1910".

6 El hecho de que las situaciones de conflicto hayan sido fijadas a mediados del siglo XIX, no quiere decir en lo absoluto que estos sean obligadamente exclusivos a este período, pudiendo dar cuenta de procesos de latencia o de crisis anteriores.

7 Entre los casos puntuales que presentan registros propietarios de carácter colectivo, encontramos la constitución del espacio de Ticnamar, que comienza su historial de propiedad en 1758, a partir de la compra de Diego Apasa en representación del "común de indios del pueblo de Tignamar", dando paso a posteriores acciones de regularización en los años 1773, 1856, 1903, 1927, 1941 y 1942 (Gundermann, 2003). Otro caso representativo lo constituye la inscripción de pastales en la localidad de Saxamar, que inicia a partir del año 1893 un proceso de fragmentación de una propiedad que en tiempos coloniales habría correspondido al común de indios de Saxamar, siendo individualizada y, posteriormente, en paños privados en un amplio historial de inscripciones (Ruz, 2008). 


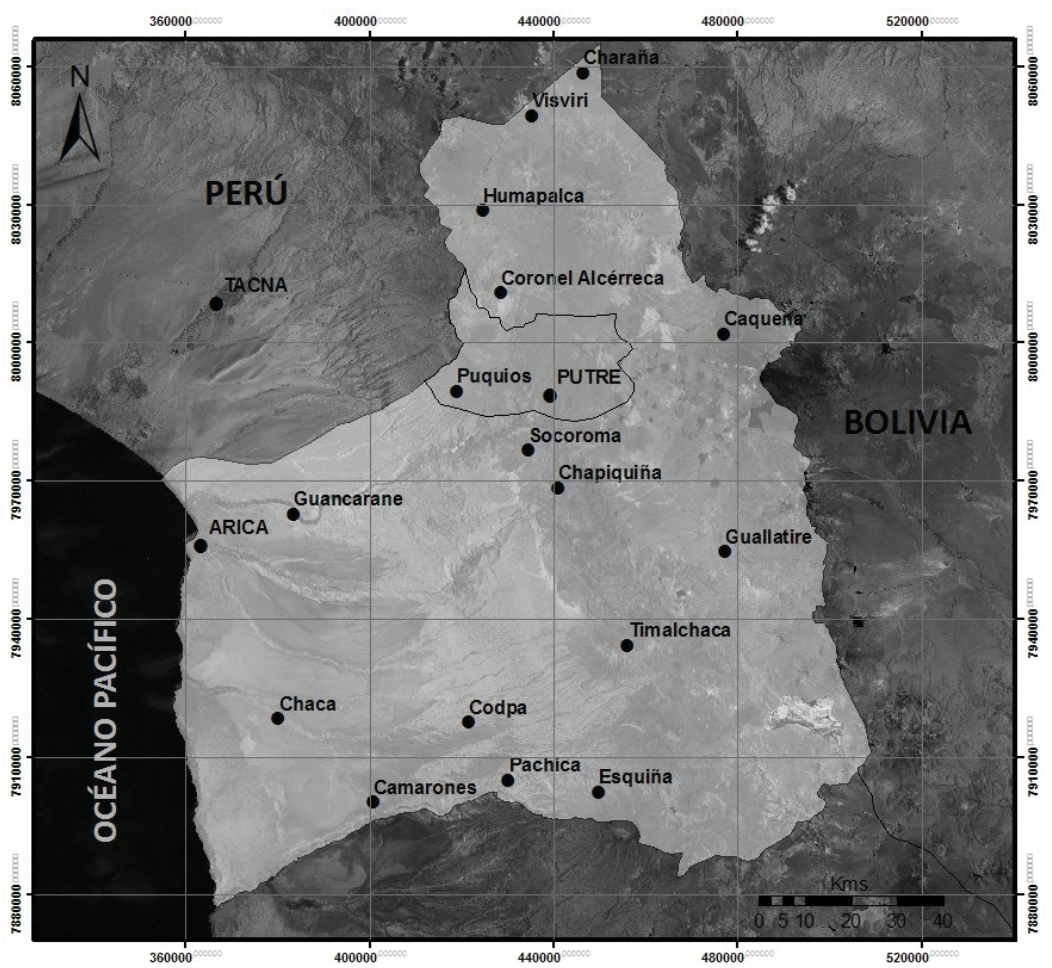

Figura 1: Espacio privado inscrito por comuneros putreños en Registros de Conservador de Bienes Raíces chilenos entre 1909 y $\mathbf{1 9 1 0}^{8}$. Por R. Ruz, y A. Díaz, 2011.

\section{Solicitudes de tierras de cultivo (Llipi Llipi), defensa y argumentación histórica}

(Archivo Nacional Judiciales de Arica [ANJA], 1872, Legajo 319, pieza 16)

La zona de cultivos denominada localmente como Llipi Llipi (Figura 2), es considerada por los vecinos del pueblo de Putre, como un antiguo sector de apropiación colectiva, que los lugareños destinaban preferentemente a la siembra de alfalfa. Este sector forma parte del área de sectores de cultivo que rodean al poblado de Putre y que son manejados con sistemas independientes de regadío. El año 1872, Micaela Guarache,

\footnotetext{
Proceso de inscripción colectiva habría sido propiciado por presiones sobre los espacios comunitarios iniciados hacia la medianía del siglo XIX.
} 
“indígena vecina de Putre, y de tránsito en esta ciudad", acude al Juzgado de Arica para solicitar la protocolización de un documento fechado en junio de 1821, a través del cual reclamaba la "posesión de los terrenos de Llipi Llipi variados en Putre adjudicados a mi finado padre Isidro Guarache".

En este documento, Isidro Guarache, "indígena ya vecino de este pueblo de Putre", solicita al Juzgado en Arica se le "guie contra Gregoria Caceres", a quien acusa de haber tapiado el sector de Llipi Llipi, argumentando que estos terrenos fueron prendados a él y a su hijo Faustino Guarache por el "señor alcalde Don Juan Madueño", en 1821 .

Este documento es presentado por Micaela Guarache como prueba para la regularización y adjudicación del predio en su calidad de heredera de Isidro. Esta presentación tuvo repercusiones dentro de la comunidad de Putre. Si bien la petición no detalla las dimensiones de predio que se solicita regularizar, del desarrollo del litigio se desprende que abarcaba una superficie que el resto de los comuneros de Putre consideró excesiva o atentatoria contra la comunidad.

El 5 de marzo de 1878, un grupo de vecinos compuestos por "Mariano Bentura, Bicente Medina, Nicolas Copa, Jose Leon Choque, Caseres, Mamani Ventura, todos vecinos labradores del pueblo de Putre" se dirigen al juez de primera instancia de Arica, replicando la solicitud y denuncia hecha por Micaela Guarache en 1872. Los argumentos de los vecinos, aparte de señalar la antigüedad de la ocupación comunitaria del sector de Llipi Llipi, enseñan el funcionamiento de las estructuras coloniales de reparto de los predios de cultivo:

de hase mas de 55 años poseemos nosotros y casi todo el vecindario de Putre, posecion reconocida y despachada desde tiempo inmemorial... [como] indijenas tributarios, entre los mismos que se encontraba el difunto padre de nuestra demandante Isidro Guarachi, a quien tambien se le adjudicó una parte.

El grupo de comuneros señala su extrañeza de que la solicitud de Guarache haya involucrado terrenos - se sugiere- que eran de acceso colectivo, es decir, disponibles para los miembros de la comunidad:

9 El documento de 1821 fue extendido en momentos previos a la independencia del Perú. Es decir, se trata de un documento todavía colonial y sujeto al sistema de repartos utilizado para la asignación de tierras. 
que hoy sorpresivamente quiere hacer extensiva a todos los terrenos del pago, que componen mucho mas de dossientos topos, de los que todos somos propietarios, siendo así que es un absurdo pretender que a este como contribuyente fuese posible que se le hubiera adjudicado un pago, un aillo, etcétera.

Dada esta calidad comunitaria del sector, se reconocen explícitamente los derechos de Guarache y de su hija:

ciertamente que reconocen como todos los propietarios en el pago, un aparte donde siempre han hecho sus sembrios, por el espacio de mas de 80 años, cuya fecha cuenta la dicha señora Guarache tiene sus poseciones la reconozcamos y respetamos.

Los comuneros son claros al señalar que Guarache pretende: "Hacer valer sus alusivos derechos contra una comunidad o pueblo integro. Dicha cuestion, como muy fácilmente se corrige, se suscitó entre la hija de nuestra demandante Isidro Guarache y Gregoria Caseres, sobre la parte que le cupo como tributario".

Lo que sobrepasaría los derechos que se le asignaron de acuerdo al antiguo sistema de repartimiento, que "debieron ser nada mas que los adjudicados como tributarios, los mismos que hoy posee la hija, constante de tres topos poco unos mas o menos".

El documento cuestiona la ambigüedad de la solicitante en la identificación de predios de cultivo o sectores que solicita: "Intentar valerse de las palabras 'los terrenos de Llipellipe' citadas en aquel fraccionado expediente, para apropiarse de un pueblo entero, es lo mismo que por ejemplo, intentar tambien apropiarse el valle integro de Asapa”.

Independiente de si la solicitud de Micaela Guarache involucre solo las tierras de cultivo que le corresponden por herencia de su padre o se trate de una pretensión mayor sobre el "sector" de Llipi Llipi, como sostienen sus oponentes, es claro que se trata de una reclamación de apropiación individual enmarcada dentro del nuevo contexto jurídico que se abre después de 1854. Curiosamente, la argumentación probatoria de ambas partes refiere al funcionamiento de las estructuras coloniales, específicamente al sistema de reparto de tierras comunitarias. 


\section{Solicitud de espacios baldíos (pampa de Anco Anco), defensa y argumen- tos de manejo colectivo}

(ANJA, 1862, Legajo 360, expediente 3)

El sector reconocido como Anco Anco, en Putre (Figura 2), responde a lo que los comuneros andinos denominan pastos de "seco" o "monte", que corresponden a sectores de cerros o pampas que circundan los pueblos centrales, donde se producen floraciones silvestres producto de las lluvias estivales. Se trata de áreas que son usadas estacionalmente, entre febrero y mayo, para el pastoreo de animales, manteniéndose el resto del año en desuso (Ruz, 2008).

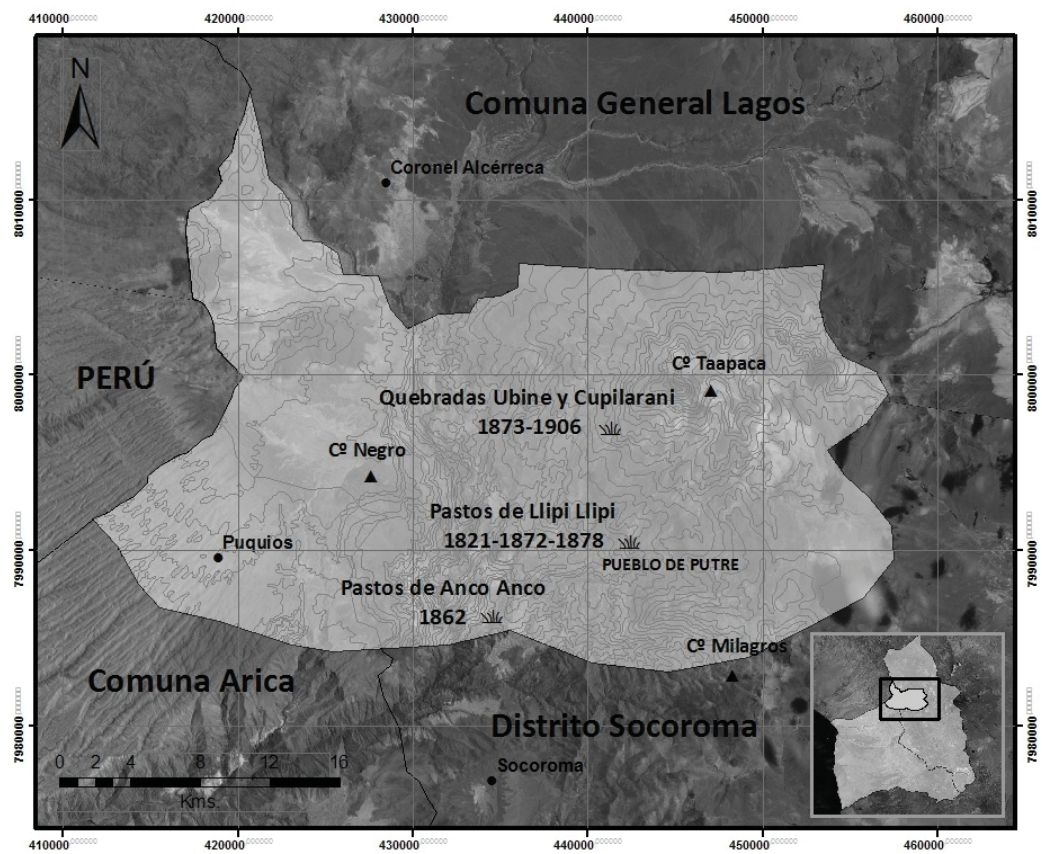

Figura 2: Pastos de uso colectivo dentro de la circunscripción del poblado de Putre, en conflicto durante el período peruano liberal. Por R. Ruz y H. González.

El 18 de diciembre de 1862, Casimiro Villanueva, vecino del poblado, entrega a Manuel Portocarrero un poder para que le represente en la denuncia de unos terrenos baldíos en Putre, una solicitud presentada el 22 de diciembre de 1862 ante el juez de primera instancia: "A un costado del pueblo de Putre se encuentran dos terrenos que desde 
tiempos inmemoriales no reconocen dueño, ni menos los han poseido persona alguna y por lo tanto no reconocen predio alguno a fabor de alguna corporación”.

Eleva esta solicitud, apelando a la condición mostrenca y vacante de los predios que tienen por deslindes:

el primer terreno algo pedregoso se alla situado por la cabesera con el serro de Sillacolloq... el pie con la asequia de Albania, por el sur el serro de Alita, por el norte las quebradas de agua caliente y grande (...) El segundo terreno de menor estencion que el primero se alla con aquel en una oyada, situados por la cabecera y costado al sur hasta el serro denominado Ancoanco, y camino que conduce del Valle de Lluta, para el de Putre norte con la quebrada que divide los alfalfares de aquel pueblo.

Pídase de cumplimiento a lo solicitado, usando los protocolos de rigor, cuestión certificada por el escribano Gavino Viscarra, quien da fe que los carteles fueron colocados en la ciudad y publicados en periódicos.

El 25 de febrero de 1863, Jorje Sarsuri y José María Huanca (antiguos vecinos del poblado) presentan una oposición a la petición de Casimiro Villanueva, indicando que los terrenos aludidos les pertenecen:

por una no interrumpida posesión de nuestros antepasados y en la que estamos nosotros. No es esto solo, esos terrenos no solo han sido poseidos por nosotros si no tambien por todos los del pueblo de Putre, que han mandado libremente sus ganaderías para que apacenten en aquellos campos; del mismo modo que cuantos han querido han cultivado sin que por ello les hubiese resultado a perjuicio.

Exigiendo sus derechos históricos y arguyendo una ocupación colectiva "por todos los del pueblo de Putre", desestiman la denuncia presentada, destacando el carácter comunal de estos terrenos. Para demostrarlo, recurren a información sumaria de los testigos "Mariano Gutierres, Vicente Manlla, Juan Mamani, Marcelo Mazuelos y Mariano Arias", vecinos de Socoroma, pueblo aledaño a Putre. Sometidos a un cuestionario donde se les consulta sobre la condición comunitaria del predio y la antigüedad de su uso, señalan que:

sí les consta que los terrenos y sembríos situados al sur de Putre, conocidos como Ancoanco pertenecen a la comunidad desde tiempo inmemorial; y que en virtud de ese 
dominio los vecinos de Putre pastan a sus animales en costumbre sin interrupcion de año en año, y por mas de cuarenta años.

Los socoromeños ven en la solicitud de Villanueva un grave en perjuicio para la comunidad de Putre, pues con ello se "monipolisaria los indicados terrenos e impediria el uso de ellos".

El 11 de abril de 1863, se presenta Manuel Portocarrero para que se realice la información sumaria de sus testigos, "Jacinto Vasquez, Doroteo Guanca, Jorge Mamani, Asencio Mamani, Saturnino Vasquez", también vecinos socoromeños, con el objetivo de desacreditar la versión de Sarsuri y Guanca, pero centrándose en su presentación como dueños de estos pastales (lo que a la luz de los antecedentes no es efectivo, ya que estos los reclaman como parte de la comunidad de Putre). Estos testigos también reconocen el carácter comunitario de este espacio, indicando que "si sabían que los vecinos de Putre llevan hacia ese lugar sus ganados", y que los putreños tienen derecho sobre "la acequia", aunque el testigo Saturnino Vásquez menciona también la presencia de cultivos en este sector, aprovechando la disponibilidad eventual de agua:

y por lo tanto ni Guanca ni Sarzuri los han poseido; pero que en tiempo del Gobierno Español el año diecinuebe del presente siglo bio correr agua en la acequia de alguaciña y que bio al pasar por el camino de Socoroma a Putre, que estaban sembradas los terrenos en una parte de ellos, pero no sabe quienes fueron los dueños.

El 17 de abril de 1863, Antonio Guanca, síndico de la Municipalidad de Putre, escribe al juez de primera instancia para oponerse también a la solicitud de los terrenos efectuada por Casimiro Villanueva. Manifiesta que conoce que los vecinos presentaron su oposición, pero que él no puede permanecer indiferente, por lo tanto, dice que:

Los terrenos de sembrio han sido propios de la comunidad aunque hace algunos años que no se cultivan o por esto han dejado de estar bajo del dominio de la comunidad asi es que tanto en los terrenos de pastales como posesion incuestionable, de suerte que hacen imposible tal adjudicación.

Clemente Vargas, en representación de Sarsuri y Guanca, el 11 de junio de 1863 oficia al juez de $1^{\circ}$ instancia para solicitar se termine con el juicio sobre la reclamación de terrenos mostrencos, señalando que se ha acreditado suficientemente la posesión de los terrenos por 40 años por parte de los vecinos de Putre, corresponde que, basado en el testimonio presentado por 14 testigos y, además, en consideración a los graves daños que 
una resolución en contrario produciría para la comunidad, que utiliza estos pastales para la mantención de su ganado.

Finalmente, el 3 de octubre de 1863, considerando los argumentos y testimonios presentados, se declara sin efecto la denuncia presentada por Villanueva por los terrenos mostrencos de la comunidad de Putre.

\section{Solicitud de pastales (Cupilarani y Ubinas) por parte de forasteros en acuerdo con comuneros locales, y defensa comunal}

(ANJA, 1873. Lejago 345, pieza 9)

Los pastales Cupilarani y Ubinas (véase Figura 2), corresponden a estancias ganaderas, con pequeños asentamientos poblados, asociadas a afloramientos de agua que permiten el crecimiento de vegas de tipo bofedal, que son utilizados para el pastoreo de ganado, esencialmente camélido, que exige movilidad en busca de forraje (Ruz, 2008).

En 1873, estos pastales fueron solicitados por "Jose Rey y Rudesindo Sarsuri, vesinos de Putre, (indígenas) de tráncito en esta ciudad", quienes denuncian ante el juzgado de $1^{\circ}$ instancia de Arica su calidad de terrenos mostrencos, es decir, vacantes o carentes de dueño: "En el cerro de Putre y en un lugar llamado Cupilarani y Uvinas, existen dos manantiales pequeños de agua, que no tienen dueño conocido ni son poseidos por nadie".

Esta solicitud, es admitida en octubre de 1873 y, de acuerdo al procedimiento vigente, se ordena que: "Publique por el termino de cuatro meses por medio de carteles que se fijaran en esta ciudad en los lugares de costumbre y por medio de uno de los periódicos de la ciudad de Tacna".

En febrero de 1874, el vecino Pedro Cáceres, a nombre de Tomás Choque, Isidro Cáceres, Manuel Ventura, José María Guanca y Manuel Mazuelos, "todos agricultores del mismo vecindario", presentan su oposición a la solicitud de Rey y Sarsuri, denunciando que: "Maliciosamente estos anuncian que no tienen dueño ni poseedor, impidiendo la respectiva adjudicación que debidamente acompaño".

Cáceres declara que la ocupación de estos "manantiales" es conocida "desde tiempo inmemorial", identificando a su tío Tomás Choque y a su abuelo Gaspar Inquiltupa como los antiguos ocupantes. Agrega que esta antigua ocupación es: 
notoria y consta á todo el vecindario de Putre de que nosotros hacemos uso de aquellas aguas para el regadio de los terrenos que se hallan en la misma quebrada por más de cuarenta años uniendo nuestra posesion á la de nuestros antepasados siendo por lo tanto sorpresiva y maliciosa la denuncia y margine cuando se ha omitido esponer que se hallaban poseidos por nosotros los manantiales de la presente cuestion.

El recurso de Cáceres incluye un documento del año 1854, cuando Mariano Villanueva, el gobernador político del distrito de Belén, autoriza a Gaspar Inquiltupa a utilizar el pastal Ubinas:

Atendiendo a los servicios que a este pueblo tiene hechos el indígena contribuyente reservado por su edad de cincuenta y cuatro años Gaspar Inquiltupa... he venido en original a como que en efecto le asigno en virtud de orden superior fiscal, un pastalsito nombrado Ubinas a distancia de tres leguas de este referido pueblo para que pueda existir allí el, y sus desendientes con sus ganaditos de ovejas y otra clase, dejandole libre de cultivar algunos terrenitos que hay a proposito en esa cordillera, y esta asignación le comprende la quebrada de Ubina desde la cordillera nombrada Tarapaca hasta el camino que cruza para Tacna nombrado Viluyo. Su cargo a las autoridades presentes o futuras le hay en reconocer y le reconozcan pastal poseedor de los pastales de Ubinas según va espresado en este título dado en Putre a 3 de Febrero de 1854.

Para la defensa de sus derechos, Cáceres también incluye en el expediente la "nueva" documentación estatal, comprobantes de pago de las contribuciones prediales canceladas por Inquiltupa entre los años 1866 y 1871 . Frente a las anteriores evidencias, Sarsuri y Rey optaron por desconocer a Cáceres como interlocutor y legítimo representante de los derechos de Choque e Inquiltupa.

El mencionado Cáseres sin tener ningun derecho a los manantiales denunciados para alucinar con su opocicion se ha habido de la astucia de cociderarse apoderado de Don Tomas Choque y demas interesados que menciona en su opocicion, protestando presentar el respectivo poder.

Dicha opocicion hecha con caracter de tal apoderado, pues terminantemente dice que se presenta no por si; si no a nombre del citado Choque y demas compartes, no ha podido ni puede ser admitida en forma legal desde que no se acompañaba el respectivo poder en forma... que pertenecieron a su abuelo Gaspar Inquiltupa de quien los han heredado conciderando como asesoria la posecion en que estuvo este; pero de esta no

54 Si Somos Americanos. Revista de Estudios Transfronterizos 
se puede deducir que hasta la fecha sean dueños, y aun dado el caso que asi fuera no han podido ni pueden ser representados por Cáseres sin el suficiente poder.

Ademas tengase presente que la madre de Cáseres e hija de Inquiltupa existe y que en este caso nadie sino ella puede reclamar sus propios derechos, y en el caso de que Cáseres como hijo quiciese aserlo, es indispensable que tuviera y acompañada el respectivo poder de haquella no siendo pues hecha la oposición con algun caracter legal, pues como lo llevamos expuesto, el mencionado Cáseres no teniendo poder de las personas a quienes representa no puede ser apoderado, es indudable que la dicha opocicion es ilusoria y debe ser desechada por la rectitud del juzgado y en cuanto a la representación que por si quisiera alegar, tampoco la tiene por que como lo llevo indicado, estando viva su madre cual heredera o Inquiltupa, no puede representar a esta sin acompañar tambien el respectivo poder de todo lo que se deduse que la dicha opocicion no puede surtir efecto alguno y debe llebarse adelante la denuncia q tenemos hecha de los manantiales negandole al citado Cáseres la personeria que pudiera tener.

La estrategia de Sarsuri y Rey enseña un manejo de los códigos y protocolos jurídicos, de la comprensión del lenguaje y procedimientos legales. Lo mismo ocurre con Cáceres, quien parece verse obligado a contactar a Manuel Ventura (¿abogado? o bien una persona letrada y conocedora del sistema legal) para representarlo en el juicio pendiente con José Rey y Rudesindo Sarsuri. De esta manera, su defensa se apega a la tradición, códigos y lenguaje jurídico:

El artículo de falta de personeria se há deducido de suspicacias y de falsas interpretaciones del escrito que presenta mi poderante Caceres, y en puerilidades que no pueden de manera alguna entorpecer el buen derecho de todos los propietarios de los manantiales en cuestion, posesion de tiempo inmemorial y a vista y paciencia de todo el vecindario de Putre, y especialmente de los denunciantes Rey-Sarsuri.

Sin embargo para cortar el proposito de los denunciantes, aparte de los documentos que ya se hallan presentados, acompaño en $13 \mathrm{~F}$ útiles el testimonio de aquellas aguas, por el que consta que han sido pedidas de una manera notoria y pública, y á mérito de resoluciones judiciales espedidas legalmente; siendo por consiguiente falso de todo punto que los manantiales de Cupilarani y Uvina no tuviesen dueño ni poseedor conocido, como lo aseguran los contrincantes. Este solo hecho; a que podria agregarse una prueba testimonial abundante y satisfactoria, entendiendo que será bastante para hacer desistir a Rey y Sarsuri de su propósito... a pesar de que esta defensa aprovechará todos los indígenas propietarios de aquellas aguas, por cuanto en la secuela del juicio 
acreditaré la propiedad de todos estos, con esta misma fecha tengo presentado el poder que ellos me han conferido para la correspondiente protocolización, cuyo testimonio presentaré oportunamente.

La defensa realizada por Ventura, basada en el reconocimiento social del uso y la legítima propiedad de los comuneros, se concretó el 14 de noviembre de 1874, casi un año después de iniciado el litigio ${ }^{10}$, cuando finalmente se resuelve que:

los manantiales denunciados, i en general a las aguas del rio i demas vertientes de $\mathrm{Pu}$ tre i la posesion no interrumpida en que han estado de ellas, i estando a lo que dispone el articulo 1389 del codigo de enjuiciamiento en materia civil: se declara sin lugar la espresada denuncia i sin efecto el auto que en ella recayó; i se mantiene a los opositores en la posesion de las aguas mencionadas.

Un dato importante está relacionado con la condición de "indígena” de Rey y Sarsuri. Mientras este último apellido de ascendencia nativa es común en Putre, José Rey no existe memoria entre los comuneros actuales. Por los antecedentes disponibles, se trataría de un comerciante ligado al negocio especulativo de propiedades y tierras. Este sujeto aparece, a comienzos del período de administración chilena, adquiriendo una importante cantidad de propiedades, las que posteriormente vende. Posiblemente, hacia fines del siglo XIX, Rey se involucró en el negocio de propiedades, aprovechando la apertura del mercado de tierras propiciado por la liberación de las trabas y seguridad que ofrecía el reconocimiento especial de las tierras indígenas por parte del Estado peruano. Esto se hace más evidente, cuando durante el período de administración chilena, entre 1887 y 1907, Rey aparece vendiendo 28 propiedades en Putre y en Chapiquiña (Hacienda Chapiquiña $)^{11}$.

10 Años después, Pedro Cáceres deberá nuevamente recurrir a tribunales para defender la posesión del pastal Ubinas ante la presión de Calisto Vilca, quien pretende "injustamente tener derechos sobre ellos". En la defensa se argumenta una "justa y pacífica posición como me he encontrado siempre de estos pastares", además de ofrecer como testigos a Pio Quea, Baldomero Giron, Juan Aguilar, Don Manuel Quiguaillo y Don Nicolás Alanoca, todos agricultores y vecinos de Putre. Archivo Departamental de Tacna [ADT], 1878, Legajo 65, Cuaderno 1960.

11 Base de datos proyecto FONDECYT 1970644. En legajo 345, № 11, 1873 (ANJA) se liquida la sociedad "Jose Rey y otro". A fs $3 \mathrm{v}$ señala que "la sociedad tiene por objeto continuar los negocios que ha hecho hasta la fecha 1 casa Jose Rey y compañía, como en compra y venta de mercaderias, recibo y despacho de aduana, recibo y despacho de cargas a Bolivia; venta i rescate de mercaderias y productos en el establecimiento de tambo Quemado i cualquiera otra negociación de que nuestro acuerdo se comprendieran". ¿Era José Rey indígena y vecino de Putre al elevar la solicitud por Uvinas?, o ¿se está frente a un proceso de apropiación de bienes indígenas?

56 Si Somos Americanos. Revista de Estudios Transfronterizos 
Finalmente, hay que señalar que el historial de conflicto por los pastales Ubina y Cupilarani, culmina en 1906, año en que son inscritos en los registros de las oficinas del Conservador de Bienes Raíces chilenos por Gregoria Cáceres, en calidad de herencia "de sus padres" 12 .

A nivel de sumario, de los casos expuestos es posible señalar la potencial y recurrente disputa de espacios de uso colectivo por parte de actores externos a la comunidad, así como también a miembros de las mismas.

En todos los casos, la respuesta de la población se expresó en el uso de los medios jurídicos pertinentes (inscripciones, solicitudes, litigación como mecanismos de negociación destinados a mantener un control paralelo a la entidad estatal), situación que define uno de los impactos de las políticas liberales en el ámbito de las relaciones Estado y comunidades indígenas.

A nivel de impactos a largo plazo, el impulso de las políticas económicas liberales que afectaron a la "comunidad" en sus dimensiones jurídicas y territoriales sobre espacios de uso colectivo precordilleranos en Arica, inician su historial hacia el año 1862, momento de apertura del expediente judicial que contiene el conflicto por los pastos de uso colectivo de Anco Anco, en el poblado de Putre.

Con este litigio, comienzan a su vez los argumentos que dan cuenta de un manejo colectivo de espacios considerados por la legislación y por los solicitantes de tierras como "baldíos", situación replicada el año 1878 en la disputa por los pastos comunales de Llipi Llipi, instancia en la que un grupo de vecinos presentan oposición a la solicitud de individualización de pasturas, donde su argumentación y defensa refiere a la condición de tierras de "reparto" asociadas originalmente a reparticiones coloniales.

Ambos casos (Anco Anco y Llipi Llipi) obedecen a pasturas y cultivos colectivos ubicados, respectivamente, en las cercanías del centro poblado de Putre, sin embargo, la documentación expuesta también identifica presiones sobre sectores altos (majadas o estancias ganaderas) circunscritas al poblado, siendo los "manantiales" de Ubina y $\mathrm{Cu}$ pilarani (1873) un ejemplo de ello. La solicitud de individualizar dichas majadas por dos

12 Registro del Conservador de Bienes Raíces de Arica [RCBR], Fojas 208 vuelta, № 691. Se trata de la única inscripción "individual" de pasturas dentro de la circunscripción Putre. Gregoria Cáceres era esposa de Antonio Mollo, un conocido comunero pro-peruano, que años después (1909 y 1910) impulsaría la inscripción colectiva de la denominada "Comunidad de Putre" en el período de administración chilena de este espacio. 
sujetos (¿ajenos a la comunidad?), se vio objetada por miembros de la colectividad de Putre, los que apoyaron a los ocupantes tradicionales de dicha estancia.

Como dato adicional, hay que señalar que el historial judicial de dichas majadas se "cierra" con posterioridad (comienzos del siglo XX), cuando la descendencia de uno de los opositores a la individualización propuesta en 1873, realiza una inscripción ante los Registro del Conservador de Bienes Raíces de Arica.

\section{Conclusiones}

Las disposiciones estatales que normaron el acceso a las tierras de uso colectivo con el Estado peruano, comenzaron a ser instrumentalizadas por la población indígena en distintos niveles, destacándose el otorgamiento de un sentido usufructuario a estas medidas, que en algunos casos llevó a que personas vieran la posibilidad de acceder a terrenos, desconsiderando los mecanismos tradicionales dispuestos por las comunidades de acceder o utilizar dichas tierras, siendo común encontrar solicitudes de personas que buscaban acceso a tierras tradicionalmente utilizadas bajo un formato de "comunidad".

El aprendizaje acuñado durante los años de interacción con los procedimientos establecidos por el gobierno y poder judicial peruano y su política en materia de tierras, otorgó a la población indígena de experticia en cuanto a procedimientos y protocolos formales e informales en procesos de solicitud, oposición, litigio, negociación y/o defensa de tierras.

La objetivación jurídica y propietaria del territorio considerado como propio por parte de un segmento de la población del poblado de Putre, sugiere que dicha intención se acuña durante el momento peruano liberal, expresándose en litigios y conflictos, en donde la concepción territorial de colectividad comenzó resguardarse en pro de intereses de miembros de la corporación.

Los procesos de entendimiento, aprendizaje y uso efectivo de los medios legales y/o políticos destinados a asegurar el espacio colectivo, se ven representados en la reacción a las presiones sobre los espacios comunales expuestos a solicitudes de individualización, fragmentación de los espacios de uso colectivo y sus consiguientes oposiciones, así como el surgimiento de intereses externos, alianzas entre "forasteros" y "locales" para impulsar solicitudes que terminaron con procesos de defensa de espacios de uso colectivo. 


\section{Referencias}

Archivo Departamental de Tacna (ADT) (1878). Legajo 65, Cuaderno 1960.

Archivo Nacional Judiciales de Arica (ANJA). (1862). Legajo 360, expediente 3.

Archivo Nacional Judiciales de Arica (ANJA). (1872). Legajo 319, pieza 16.

Archivo Nacional Judiciales de Arica (ANJA). (1873). Legajo 345, pieza 11.

Conservador de Bienes Raíces de Arica (S/F). Foja 208 vuelta, Nº 691.

Contreras, C. (1980). Estado republicano y tributo indígena en la sierra central en la postIndependencia. Histórica XIII (1), 9-44.

Dougnac, A. (1994). Manual de historia del Derecho Indiano. México: Universidad Autónoma de México.

Figallo, G. (2007). Origen, exclusión y reafirmación de las comunidades campesinas del Perú. Lima, Perú: Editorial San Marcos.

González, H. (2002). Los Aymaras de la Región de Tarapacá y el periodo republicano temprano (1821-1879), Documento de Trabajo No 45 . Santiago, Chile: Comisión Verdad Histórica y Nuevo Trato.

González, H., y Gundermann, H. (2009). Acceso a la propiedad de la tierra, comunidad e identidades colectivas entre los aymaras del norte de Chile. Chungara Revista de Antropología Chilena 41 (1), 51-70.

Gundermann, H. (2003). La formación del espacio andino en Arica y Tarapacá. Historia Indígena $7,87-138$.

Jacobsen, N. (1997). Liberalism and indian communities in Peru, 1821-1920. En R. Jackson (ed.), Liberals, the Church and Indian Peasants. Corporate Lands and the Challenge of Reform in Nineteenth-Century Spanish America (pp. 123-170). Alburquerque, New Mexico: University of New Mexico Press.

Langer, E. (1988). El liberalismo y la abolición de la comunidad indígena en el siglo XIX. Historia y Cultura 14, 59-95. 
Platt, T. (1982). Estado Boliviano y Ayllu Andino. Tierra y Tributo en el Norte de Potosí. Lima, Perú: Instituto de Estudios Peruanos.

Ots Capdequí, J. M. (1968). Historia del Derecho español en América y del Derecho indian. Madrid, España: Aguilar ediciones.

Ruz, R. (2008). Uso de pastales y construcción de circunscripciones comunitarias en la precordillera de Arica. Siglos XIX-XX. Diálogo Andino 31, 47-65.

Ruz, R., y Díaz, A. (2011). Estado chileno y comunidad indígena. Presión y conflicto sobre tierras de uso colectivo en el espacio precordillerano de Arica: Putre 1880-1935. Estudios Atacameños. Arqueología y Antropología Surandinas 42, 173-188.

Sánchez-Albornoz, N. (1978). Indios y Tributos en el Alto Perú. Lima, Perú: Instituto de Estudios Peruanos.

60 Si Somos Americanos. Revista de Estudios Transfronterizos 